\title{
Filtration pressure response to infusion of atrial natriuretic peptides
}

\author{
Jürgen Schnermann, Marcos Marin-Grez, and Josephine P. Briggs \\ Physiologisches Institut der Universität München, Pettenkoferstraße 12, D-8000 München 2, Federal Republic of Germany
}

\section{ABSTRACT}

The present experiments were undertaken to assess the effect of an atrial extract (ANF) and of the synthetic atriopeptin II (APII) on filtration pressure of rat kidneys. Continuous recordings of stop flow pressure (SFP) were made to obtain an index of the change of glomerular capillary pressure produced by atrial peptides and its time course. Short-term infusion of ANF or APII increased SFP from $40.6+0.99$ to $50.7 \pm 1.42 \mathrm{~mm} \mathrm{Hg}(p<0.001)$ and from $44.0 \pm 1.28$ to $52.7 \mp 1.75 \mathrm{~mm} \mathrm{Hg}(\mathrm{p}<0.001)$ respectively. The maximum response was achieved promptly. Return of SFP to control was slow: 20 minutes after termination of the infusion SFP was still elevated by $4.9 \pm 1.27 \mathrm{~mm} \mathrm{Hg}$ $(p<0.01)$. Tubule and stellate vessel pressures increased less than $2 \mathrm{~mm} \mathrm{Hg}$, changes that were not significant. Arterial pressure fell $6 \mathrm{~mm} \mathrm{Hg}(p<$ 0.05 ). When arterial pressure was reduced by an aortic clamp to $85-90 \mathrm{mmHg}$ prior to administration of APII the response of SFP was markedly blunted (from a mean increase of $9.0 \pm 1.07 \mathrm{~mm} \mathrm{Hg}$ to $4.5 \pm 0.53 \mathrm{~mm} \mathrm{Hg}$ ). The increase of SFP probably reflects an increase of glomerular capillary pressure. The finding suggests that atrial peptides increase glomerular filtration rate at least in part by increasing filtration pressure.

Key-words: Atrial natriuretic factor, atriopeptin II, glomerular pressure, natriuresis.

\section{INTRODUCTION}

The effect of the atrial natriuretic peptides on the process of glomerular filtration remains a subject of controversy. A number of early studies suggested that the increase of urinary sodium excretion caused by ANF was not accompanied by a change in glomerular filtration rate (de Bold et al. 1981, Keeler 1982, Pollock and Banks 1983, Sonnenberg et al.1982). However, in most recent studies GFR has been found to rise (Beasley and Malvin 1985, Burnett et al.1984, Huang et a 1. 1985, Maack et al. 1985, Seymour et a 1 . 1985). Measurements of SNGFR of superficial nephrons from our own laboratory demonstrated a dose dependency of filtration rate changes, with significant persistent elevations of filtration rate during infusion of ANF at high doses and smalier increases that did not achieve significance at lower doses(Briggs et al. 1982). A similar dose-dependent change of GFR has been observed in another study in rats (Hirata et a), 1985). The present experiments were undertaken to study the effect of atrial peptides on filtration pressure using the stop flow pressure (SFP) of single nephrons as. a measure of glomerular capillary pressure. Our results show that atrial peptides induce an immediate and Tong-lasting increase of SFP, consistent with the notion that hemodynamic alterations are an early consequence of increased plasma levels of ANF.

Offprint requests to: Jürgen Schnermann, University of Michigan Medical School, Department of Physiology, Ann Arbor, MI 48109, USA

\section{METHODS}

Experiments were performed in 215-275 g male Sprague-Dawley rats. The rats were anesthetized by intraperitonea 1 injection of $120 \mathrm{mg} / \mathrm{kg}$ inactin. Catheters were inserted into the femoral artery for pressure measurement and into the jugular vein. During the surgical preparation the rats received a $4 \mathrm{~g} \%$ albumin solution in saline in a volume corresponding to $0.5 \%$ of body weight at a rate of $1.2 \mathrm{ml} / \mathrm{hr}$ followed by a maintenance infusion of $1 \mathrm{~g} \%$ albumin in saline at 1.2 $\mathrm{ml} / \mathrm{hr}$. The left kidney was prepared for micropuncture.

To measure SFP, the pressure measuring pipette (outer diameter 3-5 $\mu$, filled with $1 \mathrm{M} \mathrm{NaCl}$ coloured with FD and $C$ Green) was inserted into a random proximal tubule segment. When passage of a small bolus of the coloured solution revealed that the puncture site was early proximal a wax block was injected into a nearby downstream segment. To measure intratubular pressure a servo-nul1 pressure device (WPI, New Haven) was used. When a stable SFP was established atrial extract (ANF) or synthetic atriopeptin II (APII) was infused intravenously over a period of 2 minutes. SFP was continuously recorded for periods of up to 30 minutes. The pipette position was controlled and adjusted when necessary. Measurements of proximal tubule free flow and stellate vessel pressures were performed before and within the first 5 min period after ANF infusion. In one series of experiments SFP responses to APII were measured in the same nephron at two different levels of arterial pressure, at normal pressure and after reducing renal arterial pressure to 80-85 $\mathrm{mm} \mathrm{Hg}$ with a suprarenal aortic clamp.

Urine was collected into tared vessels for 2 periods of $5 \mathrm{~min}$ and 2 periods of 10 min after ANF infusion. Na was measured by flame photometry. To prepare ANF, atria from 40 rats (total wet weight $4.0 \mathrm{~g}$ ) were excised, frozen in liquid nitrogen and pulverized with an electric blender. The powder was dissolved in $40 \mathrm{~m}]$ of a 10:1 mixture of $0.1 \mathrm{~N}$ acetic acid in $1 \% \mathrm{NaCl}$ and $1 \mathrm{~N} \mathrm{HCl}$ and incubated for $60 \mathrm{~min}$ at $4^{\circ} \mathrm{C}$. After 75 min centrifugation at $10,000 \mathrm{rpm}$ the precipitate was resuspended, reincubated and centrifuged. The combined supernatants were pumped through Bondapak $C_{18}$ (Sep-Pak $C_{18}$ ) cartridges in 5 consecutive runs. After rinsing with $0.7 \%$ di-fluor-acetic acid the cartridges were eluated with $3 \mathrm{~m} 1$ of $80 \%$ acetonitrile in $0.7 \%$ di-fluor-acetic acid. The eluate was dried in a vacuum at $30^{\circ} \mathrm{C}$, resuspended in $16 \mathrm{ml}$ of isotonic saline, divided into $1 \mathrm{~m} 7$ portions and kept at $-20^{\circ} \mathrm{C}$ unti 7 use. The administered volume of 200 ul contained ANF from 1 atrium.

The synthetic peptide used was atriopeptin II (supplied by Dr. L. Kinter, Smith-Kline-Beckman, Philadelphia, U.S.A.). Statistical significance was determined by the t-test for paired comparisons.

\section{RESULTS}

The effect of short-term infusion of ANF or APII on SFP, arterial pressure, volume and Na excretion is 
ARTERIAL

PRESSURE

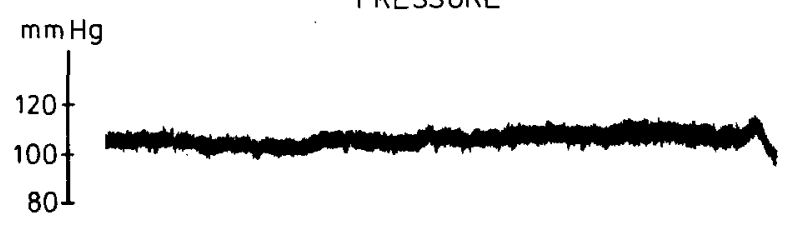

STOP FLOW

PRESSURE

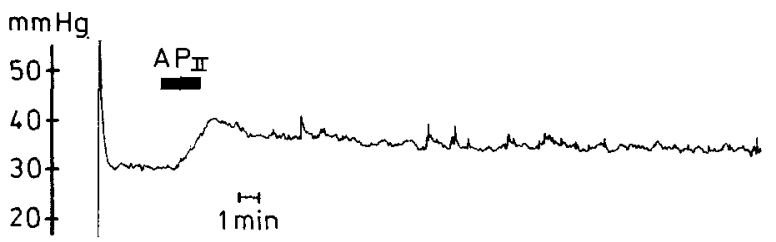

Fig.1. Original tracing showing effect of infusion of atriopeptin II on SFP

Table 1. Peak response of SFP $(\mathrm{mm} \mathrm{Hg})$, arterial pressure $(\mathrm{AP}, \mathrm{mm} \mathrm{Hg})$, urine flow $(\mathrm{V}, \mu \mathrm{l} / \mathrm{min})$, and $\mathrm{Na}$ excretion (UNaV, $\mu M / m i n$ ) to $200 \mu 1$ of atrial extract (ANF) or $500 \mathrm{ng}$ of atriopeptin II (APII)

\section{Control ANF}

Control

APII

$\begin{array}{lrr}\text { SFP } & 40.6 \pm 0.99 & 50.7 \pm 1.42 \\ \text { AP } & 114 \pm 1.42 & 110 \pm 2.7 \\ V & 7.5 \pm 1.99 & 36.5 \pm 7.69 \\ \text { UNaV } & 1.1 \pm 0.36 & 5.3 \pm 1.28\end{array}$

Rats/tubules $5 / 15$

$$
\begin{array}{cc}
44.0 \pm 1.28 & 52.7 \pm 15 \\
115 \pm 2.8 & 109 \pm 2.5 \\
3.1 \pm 0.32 & 15.8 \pm 2.2 \\
0.2 \pm 0.04 & 1.6 \pm 0.24 \\
6 / 8 &
\end{array}
$$

A 11 changes significant at $p<0.01$ or 1ess.

Table 2. Increase of stop flow pressure (SFP, $\mathrm{mm} \mathrm{Hg}$ ) produced by $200 \mu 1$ of atrial extract (ANF) or $500 \mathrm{ng}$ of atriopeptin II (APII) at different times after termination of the infusion.

$\begin{array}{ccccc} & \text { Immediate } & \underline{5} \text { min } & \underline{10} \text { min } & \underline{20} \text { min } \\ \text { ANF } & 9.4 \pm 1.57 & 8.2 \pm 1.54 & 7.2 \pm 1.64 & 4.9 \pm 1.27 \\ & p<0.001 & p<0.01 & p<0.01 & p<0.01 \\ \text { APII } & 8.3 \pm 0.46 & 6.2 \pm 0.70 & 4.7 \pm 0.54 & 1.6 \pm 0.63 \\ & p<0.001 & p<0.001 & p<0.001 & n . s .\end{array}$

summarized in Table 1. SFP increased from $40.6 \pm 0.99$ to $50.7 \pm 1.75 \mathrm{~mm} \mathrm{Hg}$ with ANF and from $44.0 \pm 1.28$ to $52.7+\overline{1} .75 \mathrm{~mm} \mathrm{Hg}$ with APII. This increase occurred despite a smal1, but significant reduction of arterial pressure. Urine volume and urinary $\mathrm{Na}$ excretion increased.

An example for the time course of the SFP increase following APII is given in Fig. 1. It can be seen that SFP began to rise shortly after start of the infusion and attained maximum values within the first minute after termination of the infusion. Table 2 demonstrates that the effect of atrial peptides on SFP is relatively long-lasting. With ANF SFP increased by a maximum of $9.46+1.57 \mathrm{~mm} \mathrm{Hg}$. After 20 minutes SFP was still significantly higher than control, by $4.9 \pm 1.27$ $\mathrm{mm} \mathrm{Hg}$. SFP changes after APII were higher than control by 10 minutes, but had approached control by 20 minutes. With both ANF and APII urinary Na excretion returned to control faster than SFP.

Mean tubule pressure was $15.2+0.37 \mathrm{~mm} \mathrm{Hg} \quad(n=14)$ in control and $16.6 \pm 0.84 \mathrm{~mm} \mathrm{Hg}(\bar{n}=12)$ in the first 5 minutes after ANF infusion (n.s.). Thus, ANF increased the pressure gradient across the glomerular capillary wall approximately as much as it increased glomerular capillary pressure. Stellate vessel pressure averaged $16.6 \pm 0.7 \mathrm{~mm} \mathrm{Hg}(n=11)$ in control and $16.0 \pm 0.8 \mathrm{~mm} \mathrm{Hg}$ $(n=8)$ during ANF infusion. Mean oncotic pressure at the end of the experiment was $19.3 \pm 1.23 \mathrm{~mm} \mathrm{Hg}(n=7)$.

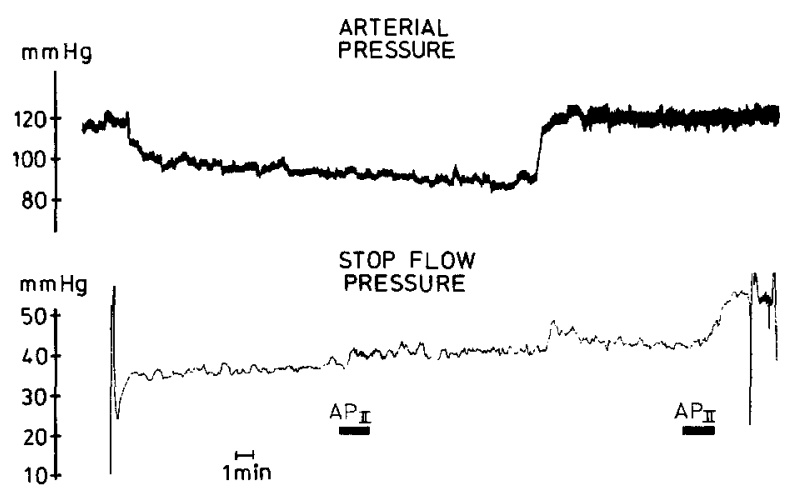

Fig.2. The effect of infusion of atriopeptin II at two Tevels of arterial pressure

Table 3 summarizes the results of studies in which SFP responses to $500 \mathrm{ng}$ APII was measured at two levels of arterial pressure in random sequence. While SFP increased from $45 \pm 2.07$ to $54 \pm 1.29 \mathrm{~mm} \mathrm{Hg}$ at normal pressure, it increased only from $36.4 \pm 1.28$ to $41.0 \pm$ when AP was reduced to $80-85 \mathrm{~mm} \mathrm{Hg}$. An example of such an experiment is shown in Fig. 2. The mean increase of $9.0+1.07 \mathrm{~mm} \mathrm{Hg}$ at normal pressure was significantly higher than the rise of $4.5 \pm 0.53 \mathrm{~mm} \mathrm{Hg}$ during the pressure reduction ( $p<0.01)$. The increase in urine flow and $\mathrm{Na}$ excretion was also markedly blunted by the pressure reduction.

Table 3. Effect of reduced arterial pressure on the SFP response to infusion of $500 \mathrm{ng}$ of atriopeptin I (APII).

\section{Control APII Reduced AP APII}

$\begin{array}{lllll}\text { SFP } & 45.0 \pm 2.07 & 54.0 \pm 1.29 * * & 36.4 \pm 1.28 & 41.0 \pm 1.43 * * \\ \text { AP } & 119 \pm 2.16 & 115 \pm 1.64 * & 89 \pm 2.55 & 88 \pm 2.64 \\ \text { V } & 3.86 \pm 0.47 & 14.17 \pm 2.57 * & 1.79 \pm 0.20 & 3.67 \pm 0.53 * \\ \text { UNAV } & 0.23 \pm 0.10 & 1.66 \pm 0.10 * & 0.10 \pm 0.03 & 0.15 \pm 0.03\end{array}$

$* p<0.02, * 0 \times 0.001$.

\section{DISCUSSION}

The present study demonstrates that an acute elevation of the plasma level of ANF by a brief infusion is followed by a prompt rise of SFP. Experimental comparisons between direct and SFP derived values for glomerular capillary pressure have indicated good agreement between the two methods in most circumstances (Arendshorst and Gottschalk 1985). But even if the estimate of GCP derived from SFP did deviate somewhat from the true GCP, the observed change in SFP following ANF almost certainly reflects a change in GCP. Any acute effects of nephron obstruction on GCP had presumably reached completion in the 5 period before ANF was given. Since continuous measurements over prolonged periods could be made, this method had the advantage of permitting the assessment of the transient behavior of filtration pressure during administration and withdrawal of the agent. However, measurements of SFP require the interruption of the tubuloglomerular feedback circuit. It is therefore possible that in the intact nephron the effect of ANF on GCP would be counter-regulated by increased distal flow, and therefore less pronounced. However ANF apppears to blunt the sensitivity of the tubuloglomerular feedback mechanism (Briggs et al. 1982), and therefore, interruption of the distal nephron feedback pathway should have relatively little effect on glomerular pressure in this setting.

Since a rise in both GFR (Beasley and Malvin 1985, 
Briggs et al. 1982, Burnett et al. 1984, Hirata et a1. 1985, Huang et a1. 1985, Maack et al. 1985, Seymour et al. 1985) and blood flow (Burnett et al. 1984, Maack et a 1 1985) are other acute responses to ANF, it seems likely that the rise of SFP is caused at least in part by preglomerular vasodilatation. Even in the absence of a persistent increase in renal blood flow (Burnett et a 1. 1984, Hirata et a1. 1985), intrarenal resistance may be reduced by these compounds since they generally produce a significant reduction of arterial pressure.

Recent results suggest that atrial natriuretic peptides do not affect the diameter of isolated afferent or efferent arterioles (Edwards 1985). Absence of a dilatory effect on glomerular arterioles has also been noted in a hydronephrotic kidney model (Marin-Grez et a 1. 1985) that permits direct visualization of vessel diameter changes (Steinhausen et al. 1985). On the other hand, both interlobular (MarinGrez et al. 1985) and arcuate arteries (Aalkjaer et a1. 1985) respond to atrial natriuretic peptides with vasodilatation. Thus, the reduction of preglomerular resistance is probably located predominantiy in those larger renal vessels which contribute to intrarenal resistance.

It is possible that postglomerular vasoconstriction may contribute to the rise of stop flow pressure. In the dog it has been shown that during constant infusion of ANF renal blood flow returns to control within a few minutes and may even fall below control values (Burnett et a 1. 1984, Maack et al. 1985). This result together with the consistent finding of an elevation in filtration fraction has been interpreted as evidence for postglomerular vasoconstriction (Beasley and Malvin 1985, Burnett et al. 1984, Huang et a1. 1985, Maack et a1, 1985, Seymour et al, 1985). A similar observation has been made in isolated kidneys that were not pre-constricted (Camargo et a?. 1984). Also, in the studies using the hydronephrotic kidney model (Steinhausen et a). 1983) it has been noted that efferent arterioles may respond to ANF with some vasoconstriction (Marin-Grez et al. 1985).

Our results show that the elevation in SFP produced by atrial peptides is long-lasting. The explanation for this observation is unclear. However, a persistent effect has also been observed in aortic strips which respond to norepinephrine with reduced constriction after transient exposure to atrial peptide (Thompson and Webb, in press). Whatever the explanation for the prolonged elevation in SFP, it is important to note that the hemodynamic alteration outlasts the natriuretic response substantially.

The effect of a given dose of ANF was much less pronounced when arterial pressure was reduced prior to administration of the agent. One may speculate that the reason for the reduced SFP response may be the reduction in baseline resistance caused by the pressure reduction to $85 \mathrm{~mm} \mathrm{Hg}$. A clear effect of baseline resistance on the response to ANF has been noted in isolated kidneys (Baines et a 1. 1983. Camargo et a 1. 1984). A vasodilatory action was on 7 y observed when these kidneys were pre-constricted. Some correlation between the natriuresis and the GCP rise following ANF is suggested by the recent observation of Davis et a]. (1985) confirmed in the present study that pressure reduction not only blunts the GCP increase, but also severely interferes with the natriuretic response.

In summary, native and synthetic ANF produce a prompt and long-lasting increase in stop flow pressure which probably reflects an increase of glomerular capillary pressure. This result provides additional evidence that these compounds have important intrarenal hemodynamic effects.
REFERENCES .

Aalkjaer C, Mulvany MJ, Nyborg NCB (1985) Atrial natriuretic factor causes specific relaxation of rat renal arcuate arteries. Brit J Pharmacol 86:447-453

Arendshorst WJ, Gottschalk CW (1985) Glomerular ultrafiltration dynamics: historical perspective. Amer J Physiol 248:F163-F174

Baines AD, deBold AJ, Sonnenberg $H$ (1983) Natriuretic effect of atrial extract on isolated perfused rat kidney. Can J Physiol Pharmacol 61: 1462-1466

Beasley D, Malvin RL (1985) Atrial extracts increase glomerular filtration rate in vivo. Amer $J$ Physiol 248: F24-F 30

Briggs JP, Steipe B, Schubert G, Schnermann J (1982) Micropuncture studies of the renal effects of atrial natriuretic substance. Pfluegers Arch 395: $271-276$

Burnett JC, Granger JP, Opgenorth TJ (1984) Effects of synthetic atrial natriuretic factor on renal function and renin release. Amer $J$ Physiol 247: F863-F866

Camargo MJF, Kleinert HD, Atlas SA, Sealey JE, Laragh JH, Maack T (1984) Ca-dependent hemodynamic and natriuretic effects of atrial extract in isolated rat kidney. Amer J Physiol 246:F447-F456

Davis CL, Schnermann J, Marin-Grez M, Briggs JP (1985) Effect of immediate and delayed reduction in renal arterial pressure on natriuresis produced by atrial natriuretic factor. Vth Eur Coll Renal Physiology, Abstract 182

DeBold AJ, Borenstein HB, Veress AT, Sonnenberg $H$ (1981) A rapid and potent natriuretic response to intravenous injection of atrial myocardial extract in rats. Life Sci 28:89-94

Edwards RM (1985) Lack of effect of atriopeptin II on glomerular arterioles in vitro. 18th Ann Meeting Am Soc Nephrol, Abstracts 184 A

Hirata $Y$, Ishii M, Sugimoto T, Matsuoka $H$, Sugimoto T, Kangawa K, Matsuo H (1985) The effects of human atrial 28-amino acid peptide on systemic and renal hemodynamics in anesthetized rats. Circ Res 57:634-639

Huang C-L, Lewicki J, Johnson LK, Cogan MG (1985) Renal mechanism of action of rat atrial natriuretic factor. J C 7 in Invest 75:769-773

Keeler $R$ (1982) Atrial natriuretic factor has a direct, prostaglandin-independent action on kidneys. Can J Physiol Pharmacol 60:1078-1082

Maack T, Marion DN, Camargo MJF, Kleinert HD, Laragh JH, Vaughan ED, AtTas SA (1985) Effects of synthetic atrial natriuretic factor (auriculin) on kidney function and the renin-angiotensin system in the dog. Kidney Int 27:316

Marin-Grez M, Dusse? R, Steinhausen M (1985) Effect of atrial natriuretic factor on the vasculature of rat kidneys. Pfluegers Arch Supp 1403, R16

Pollock DM, Banks RO (1983) Effect of atrial extract on renal function in the rat. Clin Sci $65: 47-55$

Seymour AA, Smith SG, Mazack EK, Blaine EH (1985) Renal and cardiovascular effects of rat ANF and human ANF (8-33) in conscious dogs. Fed Proc 44:1239

Sonnenberg $H$, Cupples WA, deBold AJ, Veress AT (1982) Intrarenal localization of the natriuretic effect of cardiac atrial extract. Can $J$ Physiol Pharmaco 1 60: 1149-1752

Steinhausen M, Snoei $H$, Parekh N, Baker R, Johnson PC (1983) Hydronephrosis: a new method to visualize vas afferens, efferens, and glomerular network. Kidney Int 23: 794-806

Thompson LP, Webb RC (in press) Vascular responsiveness to atriopeptin III in mineralocorticoid hypertensive rats. Hypertension 